\title{
Disentangling Between-Person and Reciprocal Within-Person Relations Among Perceived Leadership and Employee Wellbeing
}

\author{
Cort W. Rudolph ${ }^{1}$, Kimberley Breevaart ${ }^{2}$, and Hannes Zacher ${ }^{3}$ \\ ${ }^{1}$ Saint Louis University \\ ${ }^{2}$ Erasmus University Rotterdam \\ ${ }^{3}$ Leipzig University
}

(C) 2022, American Psychological Association. This paper is not the copy of record and may not exactly replicate the final, authoritative version of the article. Please do not copy or cite without authors permission. The final article will be available, upon publication, via its DOI: 10.1037/ocp0000320

This is a post-review pre-publication version of a manuscript in press at the Journal of Occupational Health Psychology (https://www.apa.org/pubs/journals/ocp). Please cite as:

Rudolph, C.W., Breevaart, K., \& Zacher, H. (2022, in press). Disentangling Between-Person and Reciprocal Within-Person Relations Among Perceived Leadership and Employee Wellbeing. Journal of Occupational Health Psychology. doi: 10.1037/ocp0000320

\section{Author Note}

Cort W. Rudolph, Department of Psychology, Saint Louis University, St. Louis, MO (USA). ID https://orcid.org/0000-0002-0536-9638

Kimberley Breevaart, Center of Excellence for Positive Organizational Psychology, Erasmus University Rotterdam, Rotterdam, The Netherlands. (D) https://orcid.org/0000-0002$\underline{8789-9447}$

Hannes Zacher, Wilhelm Wundt Institute of Psychology, Leipzig University, Leipzig, Germany. (D) https://orcid.org/0000-0001-6336-2947

This research is funded by the Volkswagen Foundation (Az. 96 849-1, "Work and Health in the Time of COVID-19: A Longitudinal Study"). Portions of this work were presented at the 2021 Virtual Conference of the European Association for Work and Organizational Psychology.

Correspondence concerning this article may be addressed to Cort W. Rudolph, Department of Psychology, Saint Louis University, Saint Louis MO (USA), e-mail: cort.rudolph@,health.slu.edu 


\begin{abstract}
Based on transactional stress theory and theoretical propositions regarding affective perceptions and reactions, we develop and test a model of reciprocal within-person relations between perceptions of directive and empowering leadership and employee emotional engagement and fatigue. A sample of $n=1,610$ employees participated in a study with a three-wave fully crossed and lagged panel design across 6 months. We used a random intercepts cross-lagged panel model (RI-CLPM) to separate within- from between-person sources of variance in leadership perceptions and employee wellbeing. Consistent with previous research, at the between-person level of analysis, we found that directive leadership was positively related to both engagement and fatigue, whereas empowering leadership was positively related to engagement and negatively related to fatigue. Interestingly, at the within-person level, we found that some of these relations occur reciprocally, in that directive leadership predicts engagement and, simultaneously, engagement positively predicts perceptions of both directive and empowering leadership. These findings challenge existing assumptions about the directionality of the association between perceived leadership and employee wellbeing and contribute to an enhanced understanding of the role of employee wellbeing for the development of leadership perceptions over time.
\end{abstract}

Keywords: Leadership, Wellbeing, Engagement, Fatigue, Longitudinal Study 


\section{Disentangling Between-Person and Reciprocal Within-Person Relations Among Perceived Leadership and Employee Wellbeing}

The association between leadership and employee wellbeing has long been examined (for reviews, see Arnold, 2017; Inceoglu et al., 2018; Skakon et al., 2010). Research generally supports positive relations between these constructs, arguing that "better" leadership is associated with higher levels of employee wellbeing (for meta-analyses, see Harms et al., 2017; Kuoppala et al., 2008; Montano et al., 2017). Yet, most research on the potential salutogenic effects of leaders on employees has been cross-sectional, adopting single-timepoint research designs (Montano et al., 2017; Rudolph et al., 2020). Such designs do not allow for strong causal inferences and, likewise, do not allow for the separation of within- from between-person sources of variance. This matters for two important reasons. First, in such designs, it is not possible to ascertain whether leadership causes employee wellbeing, whether employee wellbeing causes leadership, or whether there are potential reciprocal or mutually supportive relations between leadership and employee wellbeing. Second, as both leadership and wellbeing are dynamic phenomena, it is likely that there are different relations between leadership and wellbeing "in general" (i.e., when considered at the between-person level of analysis), compared to relations that vary and co-occur within-person, over time.

Recognizing that there are multiple ways to conceptualize the association between leadership and employee wellbeing (e.g., Arnold, 2017), we address some of the abovementioned limitations by theorizing and modeling reciprocal within-person relations between employees' perceptions of directive and empowering leadership and their emotional engagement and fatigue. We accomplish this by developing dynamic theorizing on leadership perceptions and employee wellbeing drawing from transactional theories of stress and stress 
appraisals (e.g., Lazarus \& Folkman, 1984), as well as theoretical propositions regarding affective perceptions and reactions (Lang et al., 2011). Based upon this theorizing, we test the possibility of reciprocal relations between leadership perceptions and employee wellbeing in a three-wave longitudinal study, conducted across six months. We model cross-lagged effects of these variables in a random intercepts cross-lagged panel model (RI-CLPM; Hamaker et al., 2015), which allows for the concurrent modeling of, and differentiation among, within-person and between-person effects.

As suggested, we focus on two forms of perceived leadership behaviors: directive leadership and empowering leadership (Martin et al., 2013). Directive leadership involves employees' perception that their leader provides them with specific performance goals, outlines approaches to achieve such goals, monitors their performance progress, sets clear performance standards, and offers feedback for their performance (House \& Mitchell, 1974; Martin et al., 2013; Stogdill, 1950). Empowering leadership involves employees' perception that their leader promotes their self-management and autonomous decision making, removes barriers that stand between them and their goals, and provides developmental feedback and support (Manz \& Sims, 1987; Martin et al., 2013).

Given their different foci, directive and empowering leadership present a potentially "double edged" sword when it comes to employee wellbeing. On the one hand, both directive and empowering leadership are likely to be positively associated with employee wellbeing, as they both encourage high levels of work-role investment and performance (Martin et al., 2013). On the other hand, given its task focus, directive leadership may also lead to increased strain, whereas empowering leadership, given its resource focus, may mitigate strain (Skakon et al., 2010). Following Russell's (1980) affective circumplex, we focus on two complementary forms 
of employee wellbeing: emotional engagement, which refers to the investment of employees' affective energy into their work role (i.e., high arousal, positive valence; Bakker et al., 2008; Rich et al., 2010) and emotional fatigue, which is a state of feeling “...overwhelmed, drained, and used up..." by the emotional demands imposed by the job and other people at work (i.e., low arousal, negative valence; Maslach, 1982, p. 3).

\section{Between-Person Relations Between Perceived Leadership and Employee Wellbeing}

As suggested, both directive and empowering leadership encourage work-role investment and performance, as they involve leader behaviors that provide guidance, help employees structure their work tasks, and motivate them, respectively (Martin et al., 2013). Thus, we expect that directive and empowering leadership are both positively associated with employee emotional engagement. However, owing to its inherent task focus, directive leadership is also likely to be positively associated with emotional fatigue, whereas empowering leadership, given its resource focus, is likely to be negatively associated with emotional fatigue (Skakon et al., 2010). Thus, based on the theoretically-specified nature of these forms of leadership and consistent with prior cross-sectional research on leadership and wellbeing, we expect betweenperson relations among employee perceptions of leader behavior and wellbeing outcomes:

Hypothesis 1: At the between-person level of analysis, directive leadership is positively associated with both (H1a) emotional engagement and (H1b) emotional fatigue. Hypothesis 2: At the between-person level of analysis, empowering leadership is positively associated with $(\mathrm{H} 2 \mathrm{a})$ emotional engagement and negatively associated with (H2b) emotional fatigue.

\section{Within-Person Effects of Perceived Leadership on Employee Wellbeing}


Most research on leadership and wellbeing assumes a top-down influence of leaders on employee wellbeing (e.g., Harms et al., 2017; Rudolph et al., 2020). This top-down perspective suggests that, through their enactment of various role-prescribed behaviors, leaders may exert a positive (e.g., by exhibiting individualized consideration; Rafferty \& Griffin, 2006) or a negative (e.g., by “micromanaging,” Webster et al., 2016) influence on employee wellbeing. One explanation for this top-down influence can be derived from various tenets of transactional theories of stress and stress appraisals (e.g., Lazarus \& Folkman, 1984; Scherer \& Moors, 2019), especially those which share features with theories of situation perception (e.g., Rauthmann et al., 2015). Considered in more discrete terms, various perceived leadership behaviors could be construed as either resources or threats to one's resources (i.e., stressors), and thus need to be interpreted and evaluated by employees through the process of "primary appraisal" (Lazarus \& Folkman, 1984). Indeed, the transactional stress model proposes that individuals appraise the extent to which events have bearing on their wellbeing as either irrelevant, benign-positive, or stressful through a process of primary appraisal. Moreover, such stress appraisals can be further categorized into harm-loss, threat, and challenge (Lazarus \& Folkman, 1984). After appraising a stressor, individuals assess their options, that is, what they can do to cope with a stressor through a process of secondary appraisal. The combination of primary and secondary appraisals then leads to strain, coping behaviors, and potential reappraisal processes.

The notion that the enactment of specific leader behaviors could be perceived by employees as resources or stressors is variously supported, and research on work stress identifies aspects of leaders' behavior that could serve as either resources or as stressors. For example, leaders can sanction autonomy at work, which is an important resource for bolstering employee wellbeing (Eatough \& Spector, 2014). At the same time, a lack of autonomy is a stressor 
(Spector, 1986). Likewise, leaders manage interpersonal relationships (e.g., Uhl-Bien, 2003). Interpersonal conflicts at work are construed as a stressor (De Raeve et al., 2009; Spector \& Jex, 1998), whereas close interpersonal relationships at work are an important resource closely related to employee wellbeing (Fisher, 2014). More generally, leader (mis)behavior at work has likewise been construed as a source of stress (Schyns \& Schilling, 2013), whereas more ethical leaders tend to have healthier employees (e.g., Yang, 2014).

These ideas manifest in the forms of leadership studied herein, with potential impacts on employee wellbeing. On the one hand, directive leaders set clear performance expectations and guidelines on how to accomplish performance goals (House \& Mitchell, 1974), increasing the likelihood that employees will accomplish these goals, resulting in a sense of fulfillment and motivation (Latham \& Locke, 1991; Locke \& Latham, 2006). Feedback and support from directive leaders on performance progress and goal accomplishment are valuable resources that increase the likelihood of emotional engagement (Bakker \& Demerouti, 2017; Demerouti, et al., 2001). Yet, at the same time, directive leadership may increase employees' emotional fatigue. That is, employees working with a directive leader are frequently monitored by their leader and, as such, may feel that they have little control over their work, thereby frustrating their autonomy (Deci \& Ryan, 2012). Research shows that when employees' behavior is heavily monitored by their leader, they are more likely to experience burnout, of which emotional fatigue is symptomatic (e.g., Hetland et al., 2007; Stordeur et al., 2001).

Hypothesis 3: At the within-person level of analysis, directive leadership is positively associated with subsequent emotional engagement (H3a) and emotional fatigue ( $\mathrm{H} 3 \mathrm{~b})$. On the other hand, empowering leaders motivate employees to accomplish goals by providing them with autonomy and support, resources that are well-established predictors of high 
wellbeing and low strain (Bakker \& Demerouti, 2017; Demerouti et al., 2001). Indeed, empowering leadership has been shown to increase employee work engagement (e.g., Albrecht \& Andreetta, 2011; Tuckey et al., 2012) as well as psychological capital (e.g., Ahearne et al., 2005; Park et al., 2017). As such, we expect empowering leaders to provide employees with support, energy, and the motivation to invest this energy into their work role, thus increasing their emotional engagement and decreasing their emotional fatigue.

Hypothesis 4: At the within-person level of analysis, empowering leadership is positively associated with subsequent emotional engagement (H4a) and negatively associated with subsequent emotional fatigue (H4b).

\section{Within-Person Effects of Employee Wellbeing on Perceived Leadership}

We also propose a countervailing explanation for the relation between perceived leadership and employee wellbeing, namely that it is also likely that employee wellbeing influences leadership perceptions. We base this alternative explanation on work by Lang et al. (2011), which offers that both affective perceptions and affective reactions can account for the influence of wellbeing on perceived environmental characteristics. Lang et al. (2011) developed a model of dynamic relations between depression and justice perceptions based on the idea of stress appraisals derived from Lazarus and Folkman (1984). In their model, Lazarus and Folkman (1984) refer to a "process orientation," and posit the existence of reciprocal causation between, on the one hand, people's perception of their environment (e.g., their leader's behaviors) and, on the other hand, their reactions to the environment (e.g., their wellbeing). This process orientation is embodied in the notion that "...the person and the environment are in a dynamic relationship that is constantly changing and ... that this relationship is bidirectional, with the person and the environment each acting on the other" (Folkman, 1984, p. 840). 
Recognizing that affect is an important component of wellbeing (e.g., Clark, et al., 1994; Lonigan et al., 2003), the perception assumption offers that the various ways that one views their leader are influenced to some degree by one's positive and negative affective states. To this end, research that considers relations between wellbeing and environmental appraisal finds that those with lower wellbeing perceive their environment as more threatening and riskier (e.g., Alloy \& Abramson, 1979; Lang et al., 2011). The reaction assumption offers that employee's wellbeing affects how they perceive their leader via leader's behavior directed toward their employees. That is, employees with lower wellbeing may perceive their leaders differently, because they may actually be treated differently by their leaders as a result of their lowered state of wellbeing. Thus, considering both perception and reaction assumptions, we expect the potential for a countervailing directional, within-person association with employee wellbeing preceding perceived leadership.

To this end, following from the notions of affective perceptions and reactions, high emotional engagement may make employees more perceptive to positive features of their work environment, including their leader's behavior, as emotional engagement is often accompanied with the experience of positive emotions such as hope and optimism (e.g., Fredrickson, 2013; Ouweneel et al., 2012a, 2012b). Additionally, leaders may act more directive and empowering toward emotionally engaged employees, because they trust that these employees have the capability and motivation to invest this form of affective energy into their work. That is, emotionally engaged employees have the personal resources that directive and empowering leaders encourage (e.g., self-efficacy, personal initiative, self-esteem, optimism; Hakanen et al., 2008; Xanthopoulou, et al., 2009). Such resources help emotionally engaged employees demonstrate their ability to take on the responsibilities afforded by their leader. 
Hypothesis 5: At the within-person level of analysis, emotional engagement is positively associated with subsequent directive (H5a) and empowering (H5b) leadership.

Emotionally fatigued employees, in contrast, are more likely to be perceptive of directive leadership and less likely to be perceptive of empowering leadership, because they need more external structure and tend to show less extra effort in the workplace (e.g., Chi \& Liang, 2013; Cole et al., 2010). Leaders may act more directive and less empowering toward emotionally fatigued employees because they want them to complete their tasks and guide them accordingly, but they do not encourage behaviors that fatigued employees do not have the energy for, such as setting their own goals, taking initiative, and problem solving (Sims et al., 2009). Additionally, as directive leaders closely monitor employees' behaviors, the tendency of fatigued employees to withdraw from the workplace may trigger more directive leadership as fatigue and withdrawal jeopardize the accomplishment of work goals (Blanchard et al., 1993).

Hypothesis 6: At the within-person level of analysis, emotional fatigue is positively associated with subsequent directive (H6a) and negatively associated with subsequent empowering (H6b) leadership.

\section{Method}

\section{Open Science Practices}

All data and code to reproduce the analyses reported in this paper, along with full results of all focal, exploratory, and supporting analyses, are available in our online appendix: https://osf.io/46crq/. Data for this study were collected as part of a larger longitudinal data collection effort, and so far five other studies based on the same dataset, but with completely different research questions and completely different substantive variables, have been published 
(Koziel et al., 2021; Rudolph \& Zacher, 2021; Zacher \& Rudolph, 2021a; Zacher \& Rudolph, 2021b, Zacher et al., 2021).

\section{Design, Participants, and Procedure}

We used a three-wave, fully crossed and lagged panel survey design across six months, with time lags of three months between each survey. We chose time lags of three months to be consistent with recommendations to adopt relatively shorter lags in longitudinal panel studies (Dormann \& Griffin, 2015). Longitudinal research on leadership and employee wellbeing has typically used longer time lags (e.g., six months to one year, or longer; see Nielsen et al., 2008). However, based on existing studies that have adopted shorter time lags (e.g., Niessen et al., 2017; Volmer et al., 2011), we consider three months as an appropriate time frame for over time dynamics in employees' perceptions of both leadership and their wellbeing to emerge.

To recruit participants, we commissioned a professional and certified panel company to sample from a nationally representative online panel in Germany. To be eligible to participate, employees had to be at least 18 years old and be working full-time. The company sampled participants broadly from all 16 German states and from various occupations. For the initial survey conducted at the beginning of December of 2019 (Time [T] 1), $n=4,839$ persons in the company's database were contacted and $n=2,439$ employees initiated the survey and provided at least partial responses (e.g., demographics, leadership, wellbeing; response rate of 50.4\%). At each subsequent time point, these $n=2,439$ participants were recontacted by the panel company and invited to participate. Specifically, T1 participants were re-contacted three months after the T1 survey, at the beginning of March 2020 (T2, $n=1,521$ respondents), and six months after the T1 survey, at the beginning of June 2020 (T3, $n=1,173$ respondents). In total, $n=1,610$ of the initial $n=2,439$ participants provided at least partial responses on demographic and/or 
substantive variables from T1 to T3, constituting the sample we consider here; $n=958$

participants provided complete responses at $\mathrm{T} 1$ to $\mathrm{T} 3$.

A summary of participant demographics can be found in Table 1. Across the three waves of this study, some degree of attrition was observed. To understand the nature of attrition, we compared incomplete responders $(n=829)$ with panel responders $(n=1,610)$ on several demographic and substantive variables measured at T1 (see Table 1). In a logistic regression model, these predictors only accounted for . $2 \%$ of the variability in observed attrition $\left(R^{2}\right.$ Cox \& Snell $=.002$ ). As such, we are confident that systematic attrition is not of principle concern here (see online appendix for complete analysis).

\section{Measures}

For each of the substantive measures collected at each measurement wave participants were instructed to think about the past three months at work in providing their ratings.

Directive and empowering leadership. Six items from Martin et al.'s (2013) measure of directive leadership ( 3 items, $\alpha_{\text {range }}=.846$ to .849$)$ and empowering leadership ( 3 items, $\alpha_{\text {range }}=$ .857 to 884 ) were used collected. These items were scaled with a 7-point response scale that ranged from 1 [never] to 7 [always]. Example items are: "My supervisor monitored employee performance" (directive) and "My supervisor taught employees how to solve problems on their own" (empowering).

Emotional engagement. Three items from Rich et al.'s (2010) emotional job engagement scale were collected to assess emotional engagement ( $\alpha_{\text {range }}=.904$ to .922). These items were scaled with a 7-point response scale that ranged from 1 [strongly disagree] to 7 [strongly agree]. An example item is: "I was enthusiastic in my job." 
Emotional fatigue. Three items from Frone and Tidwell's (2015) emotional fatigue scale were collected to assess emotional fatigue $\left(\alpha_{\text {range }}=.902\right.$ to .935$)$. These items were scaled with a 7-point response scale that ranged from 1 [never] to 7 [always]. An example item is: "I felt emotionally worn out at the end of the workday."

Demographics. We assessed several key participant demographics as part of the T1 survey (see Table 1). Specifically, we assessed chronological age (i.e., years since birth), sex (i.e., coded as $1=$ "male"; 2 = "female"), educational attainment (i.e., coded as $1=$ "Lower Secondary School" to 4 = "College/University or Technical College"), and monthly household income (i.e., coded as $1=$ "€0-999/Month" to 7 = "€6,000-6,999/Month").

\section{Analyses}

All analyses were conducted in a structural equation modeling (SEM) framework using the 'lavaan` package (Rosseel, 2012) for R. In specifying all models, a maximum likelihood estimator was used; full information maximum likelihood (FIML) was used to account for missingness. Confirmatory factor analyses were initially run to support measurement model fits and longitudinal measurement invariance (i.e., invariance across time), both of which were upheld; for the sake of space, complete results of these analyses are available in our online appendix. All hypotheses were tested simultaneously using a random intercepts cross-lagged panel model (RI-CLPM; Hamaker et al., 2015; see Figure 1 for a general depiction).

\section{Results}

Table 1 contains descriptive statistics on the demographics of our sample, and Table 2 presents descriptive statistics and intercorrelations among substantive variables. Our hypotheses pertain to within-person relations, rather than over-time changes. Thus, to ascertain whether there were over-time changes, initially, we specified two RI-CLPM models, the first allowing 
over-time parameters (i.e., autoregressive and cross-lagged effects) to vary over time (i.e., the unconstrained RI-CLPM) and the second fixing these over-time parameters to equality (i.e., the constrained RI-CLPM; see Hamaker et al., 2015; Mulder \& Hamaker, 2021; Orth et al., 2021). The constrained RI-CLPM fit the data well $\left(\chi^{2}=53.351, d f=32, p=.010, \mathrm{CFI}=.997, \mathrm{RMSEA}\right.$ $=.020, \mathrm{SRMR}=.024)$ and did not fit significantly differently than the unconstrained RI-CLPM $\left(\Delta \chi^{2}=32.08, d f=26, p=.191\right)$. Thus, in service of parsimony and consistent with our hypotheses, the results reported here are based on the constrained RI-CLPM. Table 3 contains relevant parameter estimates from the constrained RI-CLPM, and complete results of this model are available in our online appendix.

At the between-person level of analysis, we found that directive leadership was positively correlated with both emotional engagement $\left(r_{x y}=.136\right)$ and emotional fatigue $\left(r_{x y}=.174\right)$, supporting Hypotheses 1a and 1b. Moreover, empowering leadership was positively correlated with emotional engagement $\left(r_{x y}=.389\right)$ and negatively correlated with emotional fatigue $\left(r_{x y}=\right.$ $.170)$, supporting Hypotheses $2 \mathrm{a}$ and $2 \mathrm{~b}($ all $p<.05)$.

At the within-person level of analysis (see Table 3), we observed a significant $(p<.05)$ and positive cross-lagged effect of directive leadership on emotional engagement $(B=.100)$, but not on emotional fatigue. Empowering leadership did not have significant effects on wellbeing at the within-person level. Thus, Hypothesis 3a was supported, whereas Hypotheses $3 \mathrm{~b}$ as well as $4 \mathrm{a}$ and $4 \mathrm{~b}$ were not supported. Additionally, and in support of Hypotheses $5 \mathrm{a}$ and $5 \mathrm{~b}$, we observed two significant reverse cross-lagged effects, suggesting that employees' emotional engagement predicted perceptions of both directive leadership $(B=.128)$ and empowering leadership $(B=.144)$. Finally, emotional fatigue did not significantly predict leadership perceptions and, thus, Hypotheses $6 \mathrm{a}$ and $6 \mathrm{~b}$ were not supported. 


\section{Robustness Checks and Sensitivity Analyses}

To gauge the robustness of our conclusions observed at the within-person level of analysis, we conducted sensitivity analyses proposed by Frank (2000) and Frank et al. (2013) to gauge the (potential) influence of omitted variables. To supplement this, we also conducted a sensitivity analysis considering five covariates: (a) work demands, (b) positive affect and negative affect, (c) degree of contact between leaders and employees, (d) remote work status, and (e) exposure to COVID-19. These exogenous covariates were treated as orthogonal to oneanother due to convergence issues with models specifying oblique covariances. Bolstering the confidence we have in our conclusions, we find that omitted variables are likely not of great concern to our within-person relations, and that the inclusion of covariates decreased the fit of our focal model to the data. Complete results are available in our online appendix.

\section{Discussion}

We found some support for the proposition that employee perceptions of leadership and wellbeing have mutually reinforcing cross-lagged effects at the within-person level of analysis. Consistent with transactional theories of stress and stress appraisals (e.g., Lazarus \& Folkman, 1984) and the notions of affective perceptions and reactions (Lang et al., 2011), perceptions of directive leadership not only positively predicted employee emotional engagement, but emotional engagement also positively predicted perceptions of both directive and empowering leadership. In contrast to results at the between-person level, which were consistent with theory and meta-analytic work (Harms et al., 2017; Kuoppala et al., 2008; Montano et al., 2017), at the within-person level we did not find effects of directive leadership on emotional fatigue or of empowering leadership on emotional engagement or fatigue. Moreover, employees' emotional fatigue did not predict their perceptions of leadership. 
Interestingly, we also found some non-significant relations between perceptions of leadership and employee wellbeing at the within-person level. First, perceptions of directive leadership were not related to employees' emotional fatigue. One possible explanation for this finding could be that directive leaders are both resource draining (e.g., by limiting the amount of control employees have over their work) and resource building (e.g., by providing feedback and support). Additionally, we found no support for the hypothesized relations between perceptions of empowering leadership and both employee emotional engagement and emotional fatigue at the within-person level of analysis. It could be that these relations are dependent on certain contextual factors, such as employees need for leadership (De Vries, 1997). The extent to which employees need guidance from their leader toward goal achievement (i.e., need for leadership) depends on a variety of circumstances, such as employees' feelings of competence to complete a certain task, and may fluctuate accordingly. As such, empowering leadership may enhance employee's emotional engagement and reduce their emotional fatigue in some situations but may reduce their emotional engagement and increase their emotional fatigue in others.

We also noted that the standardized effect from emotional engagement to empowering leadership was slightly higher than the standardized effect from emotional engagement directive leadership (see Table 3). While interesting, we are cautious to interpret the differential strength of these effects as being theoretically meaningful, as we note that the $95 \%$ confidence intervals defining these relations overlap with one-another. Thus, while the absolute magnitude of these relations may be different, the difference between them is likely to be non-significant.

Finally, emotional fatigue was unrelated to employees' perceptions of directive and empowering leadership at the within-person level. One reason for these findings could be that, regardless of whether their leader behaves differently toward them, fatigued employees may not 
pay a great deal of attention to these behaviors. Contrary to positive experiences such as emotional engagement, which broaden people's views, negative experiences such as emotional fatigue narrow people's attention to their environment (Fredrickson, 2013). As such, it could be that the perception assumption (Lang et al., 2011) does not apply here and employees' emotional fatigue does not affect their perceptions of their leaders' behaviors. Another explanation may be that, in contrast to the reaction assumption (Lang et al., 2011), leaders do not change their behavior according to employees' emotional fatigue, because one way in which emotionally fatigued employees cope with their situation is through perseverance and reluctance to ask for social support (Van Dam, 2021). As emotionally fatigued employees may not admit to themselves that they must slow down and recover, their leaders are unlikely to signal what is going on, and as such, have no reason to change their behavior.

\section{Theoretical and Practical Implications}

Overall, these findings contribute to an enhanced understanding of the reciprocal nature of leadership perceptions and wellbeing and answer the call for more longitudinal research in the study of these processes (e.g., Skakon et al., 2010). Moreover, these findings challenge existing assumptions about the directionality of the relation between perceived leadership and employee wellbeing, with implications for both theory and practice. Most notably for theory, this study both challenges and extends the commonly understood idea that leadership exerts a top-down influence (i.e., from leaders to their employees) on employee wellbeing. The findings that employee wellbeing reinforces leadership perceptions, especially that employees' emotional engagement is associated with higher subsequent levels of both directive and empowering leadership, suggests also a "bottom-up" relation between employee wellbeing and perceived leadership (i.e., in a hierarchical sense, employee wellbeing exerts an "upward" influence on 
perceptions of their leader's behavior). The observed simultaneous cross-lagged relations between directive leadership and emotional engagement and emotional engagement and directive leadership suggests that both top-down (i.e., from leader to employee) and bottom-up (i.e., from employee to leader) processes co-occur and are likely to be mutually reinforcing over time. Moreover, this paper extends the notions of affective perceptions and reactions based upon the interpretation of stress appraisal theory advanced by Lang et al. (2011), from research on organizational justice and clinical depression to the context of perceived leadership and employee wellbeing.

In terms of practical implications, this study confirms the long-held notion that leadership is important for employee wellbeing, but also highlights that this relation is more complex than previously understood. This study specifically highlights the importance of both employees' perception of their leader's general behavioral pattern (i.e., between-person relations) as well as their perceptions of their leader's short-term behaviors (i.e., within-person relations). Generally, organizations should focus on ways to increase employee emotional engagement and reduce fatigue (e.g., through work design, efforts to change "overwork" cultures; see similar recommendations by Inceoglu et al., 2018). Importantly, our findings regarding the effects of emotional engagement on perceptions of both directive and empowering leadership suggest that, in doing so, perceptions of leadership may be positively affected as well. Additionally, leadership training and development programs should be designed to help promote engagement and curtail fatigue. Our results suggest that employees' wellbeing affects their perception of their leader's behaviors. As such, organizations can take measures that are likewise mutually reinforcing, for example, by hiring empowering leaders and taking additional measures to enhance employees' wellbeing (which consequently affects employees' perception 
of leadership). To this point, in this study, observed relations at the between-person level of analysis suggest that although both directive and empowering leadership are positively related to emotional engagement, directive leadership is associated with higher fatigue on average, whereas empowering leadership is associated with lower fatigue on average.

\section{Limitations and Future Research}

No study is without limitations, and although the longitudinal research design employed here is a strength of our study, future research should endeavor to extend this work. First, it is worth pointing out that we only considered self-report measures of both perceived leadership and employee wellbeing, and data were collected from a single source (i.e., employees), with no data collected from leaders. Although arguably employees themselves are the "best source" to report on their wellbeing, research has shown that leadership ratings are subject to various person-level influences, such as personality and affect (see Felfe \& Schyns, 2010; Hansbrough et al., 2015), and, as we show, their own wellbeing. Future research should consider self- and other-reports and strive to obtain data from both leaders and their employees from intact workgroups to study the reciprocal effects of leadership and employee wellbeing. Such research would also allow for further testing the idea of "top down" and "bottom up" processes as emergent qualities of workgroups that manifest as shared perceptions of employee wellbeing and leadership.

Moreover, although we focus on perceived leadership here, researchers would be well advised to collect both subjective (e.g., perceptual) and objective (e.g., behavioral) measures of leadership (e.g., observations of leader's actions), but also recognize that the latter are not necessarily a panacea to the study of leadership (e.g., Lord et al., 2017). Still, leadership research should consider both subjective and objective leadership behaviors to better understand the correspondence (or lack thereof) between these differing conceptualizations. 
Second, although we focused on the specific constructs of directive and empowering leadership, other leadership constructs (e.g., leader-member exchange, see Gottfredson et al., 2020; respectful leadership, see Rudolph et al., 2021) and wellbeing indicators (e.g., physical health, job satisfaction) may operate in similar or different ways. Future research should pit various leadership constructs against one-another (including measures of "healthy leadership," see Rudolph et al., 2020) to better understand the role of these various leadership constructs in the prediction of employee wellbeing.

Third, as suggested, we considered a time lag of three months between each survey in our study based on previous research on perceptions of leadership and employee wellbeing, and best practice recommendations (e.g., Dormann \& Griffin, 2015). However, there is not a clear theory to suggest the time frames over which these effects occur. Additionally, we consider only three waves of data in our study, and it is possible that these effects might occur differently across a longer span of time, or manifest as variability that only a design with more (and more frequent) observations could detect. Future research should endeavor to build a stronger theory for "when" the effects of leadership affect employee wellbeing and vice-versa to help establish optimal time lags and time frames to study these effects. To this end, researchers are encouraged to use continuous time approaches to establish such parameters (Rauvola et al., 2021).

Future research should also examine mechanisms and moderators of relations between leadership and employee wellbeing at the between- and within-person levels of analysis. For instance, substitutes for leadership theory (Kerr \& Jermier, 1978) suggests that other workrelated factors, such as job characteristics, team factors, or organizational climate, may compensate for a lack of beneficial leadership behavior in predicting employee wellbeing. Likewise, based on stress appraisal theory (Lazarus \& Folkman, 1984), it could be argued that 
effects of employee wellbeing on perceived leadership depend on employees' beliefs regarding the causes of their wellbeing and their evaluation of available coping resources. Similarly, experiments/interventions (e.g., Gerlach et al., 2021) and daily/weekly diary studies (e.g., Breevaart \& Zacher, 2019) could be employed (using the suggestions provided here) to better understand the causal and short term (respectively) implications of leadership for employee wellbeing and vice-versa. Finally, it is important to note that the measurement of directive and empowering leadership is challenging, and few well-developed measures of these constructs exists. Most research that assesses directive and empowering leadership constructs uses measures adapted from scales developed for other purposes (e.g., Kahai et al., 2004; Li et al., 2018; Vecchio et al., 2010). The exception to this is the Martin et al. (2013) measure used here, however this scale does not have a large body of psychometric evidence supporting its use. Thus, we echo calls found elsewhere (e.g., Rudolph et al., 2021) to improve the quality of measurement tools used to study leadership phenomena. 


\section{References}

Ahearne, M., Mathieu, J., \& Rapp, A. (2005). To empower or not to empower your sales force? An empirical examination of the influence of leadership empowerment behavior on customer satisfaction and performance. Journal of Applied Psychology, 90(5), 945955. https://doi.org/10.1037/0021-9010.90.5.945

Albrecht, S. L., \& Andreetta, M. (2011). The influence of empowering leadership, empowerment and engagement on affective commitment and turnover intentions in community health service workers: Test of a model. Leadership in Health Services, 24, 228-237. http://dx.doi.org/10.1108/17511871111151126

Alloy, L. B., \& Abramson, L. Y. (1979). Judgment of contingency in depressed and nondepressed students: Sadder but wiser? Journal of Experimental Psychology: General, 108(4), 441-485. https://doi.org/10.1037/0096-3445.108.4.441

Arnold, K. A. (2017). Transformational leadership and employee psychological well-being: A review and directions for future research. Journal of Occupational Health Psychology, 22(3), 381-393. https://doi.org/10.1037/ocp0000062

Bakker, A. B., \& Demerouti, E. (2017). Job demands-resources theory: Taking stock and looking forward. Journal of Occupational Health Psychology, 22(3), 273285. https://doi.org/10.1037/ocp0000056

Bakker, A. B., Schaufeli, W. B., Leiter, M. P., \& Taris, T. W. (2008). Work engagement: An emerging concept in occupational health psychology. Work \& Stress, 22(3), 187-200. https://doi.org/10.1080/02678370802393649

Blanchard, K. H., Zigarmi, D., \& Nelson, R. B. (1993). Situational leadership after 25 years: A retrospective. Journal of Leadership Studies, 1(1), 21-36. 
https://doi.org/10.1177/107179199300100104

Breevaart, K., \& Zacher, H. (2019). Main and interactive effects of weekly transformational and laissez-faire leadership on followers' trust in the leader and leader effectiveness. Journal of Occupational and Organizational Psychology, 92(2), 384-409. https://doi.org/10.1111/joop.12253

Chi, S.-C. S., \& Liang, S.-G. (2013). When do subordinates' emotion-regulation strategies matter? Abusive supervision, subordinates' emotional exhaustion, and work withdrawal. The Leadership Quarterly, 24(1), 125-137. https://doi.org/10.1016/j.leaqua.2012.08.006

Clark, L. A., Watson, D., \& Mineka, S. (1994). Temperament, personality, and the mood and anxiety disorders. Journal of Abnormal Psychology, 103, 103-116. https://doi.org/10.1037/0021-843X.103.1.103

Cole, M. S., Bernerth, J. B., Walter, F., \& Holt, D. T. (2010). Organizational justice and individuals' withdrawal: Unlocking the influence of emotional exhaustion. Journal of Management Studies, 47(3), 367-390. https://doi.org/10.1111/j.1467-6486.2009.00864.x

Deci, E. L., \& Ryan, R. M. (2012). Self-determination theory. In P. A. M. Van Lange, A. W. Kruglanski, \& E. T. Higgins (Eds.), Handbook of theories of social psychology (p. 416436). Sage Publications Ltd.

Demerouti, E., Bakker, A. B., Nachreiner, F., \& Schaufeli, W. B. (2001). The job demandsresources model of burnout. Journal of Applied Psychology, 86(3), 499-512. https://doi.org/10.1037/0021-9010.86.3.499

De Raeve, L., Jansen, N. W., van den Brandt, P. A., Vasse, R., \& Kant, I. J. (2009). Interpersonal conflicts at work as a predictor of self-reported health outcomes and occupational 
mobility. Occupational and Environmental Medicine, 66(1), 16-22. http://dx.doi.org/10.1136/oem.2007.037655

De Vries, R. E. (1997). Need for leadership: A solution to empirical problems in situational theories of leadership. Unpublished dissertation, Tilburg University.

Dormann, C., \& Griffin, M. A. (2015). Optimal time lags in panel studies. Psychological Methods, 20(4), 489-505. http://dx.doi.org/10.1037/met0000041

Eatough, E. M., \& Spector, P. E. (2014). The role of workplace control in positive health and wellbeing. In P. Chen and C. L. Cooper (Eds.), Wellbeing: A Complete Reference Guide (pp. 91-110). Chichester, UK: Wiley Blackwell.

Felfe, J., \& Schyns, B. (2010). Followers' personality and the perception of transformational leadership: Further evidence for the similarity hypothesis. British Journal of Management, 21(2), 393-410. https://doi.org/10.1111/j.1467-8551.2009.00649.x

Fisher, C. (2014). Conceptualizing and measuring wellbeing at work. In P. Chen and C. L. Cooper (Eds.), Wellbeing: A Complete Reference Guide (pp. 91-110). Chichester, UK: Wiley Blackwell

Folkman, S. (1984). Personal control and stress and coping processes: A theoretical analysis. Journal of Personality and Social Psychology, 46, 839-852. https://doi.org/10.1037/0022-3514.46.4.839

Frank, K. (2000). Impact of a confounding variable on the inference of a regression coefficient. Sociological Methods and Research, 29 (2), 147-194

Frank, K. A., Maroulis, S., Duong, M., \& Kelcey, B. (2013). What would it take to change an inference? Using Rubin's causal model to interpret the robustness of causal inferences. Education, Evaluation and Policy Analysis, 35 437-460. 
https://doi.org/10.3102/0162373713493129

Fredrickson, B. L. (2013). Chapter one-Positive emotions broaden and build. In P. Devine \& A. Plant (Eds.), Advances in Experimental Social Psychology (Vol. 47, pp. 1-53). Academic Press. https://doi.org/10.1016/B978-0-12-407236-7.00001-2

Frone, M. R., \& Tidwell, M. C. O. (2015). The meaning and measurement of work fatigue: Development and evaluation of the three-dimensional work fatigue inventory (3D-WFI). Journal of Occupational Health Psychology, 20(3), 273-288. https://doi.org/10.1037/a0038700

Gerlach, F., Rosing, K., \& Zacher, H. (2021). Flexible adaptation of leader behavior: An experimental analysis of the beneficial effect of flexibility in innovation processes. Journal of Personnel Psychology, 20(4), 198-206. http://dx.doi.org/10.1027/1866$\underline{5888 / \mathrm{a} 000274}$

Gottfredson, R. K., Wright, S. L., \& Heaphy, E. D. (2020). A critique of the leader-member exchange construct: back to square one. The Leadership Quarterly, 31(6), 101385. https://doi.org/10.1016/j.leaqua.2020.101385

Hakanen, J. J., Perhoniemi, R., \& Toppinen-Tanner, S. (2008). Positive gain spirals at work: From job resources to work engagement, personal initiative and work-unit innovativeness. Journal of Vocational Behavior, 73(1), 78-91. https://doi.org/10.1016/j.jvb.2008.01.003

Hamaker, E. L., Kuiper, R. M., \& Grasman, R. P. P. P. (2015). A Critique of the Cross-Lagged Panel Model. Psychological Methods, 20(1), 102-116. https://doi.org/10.1037/a0038889

Hansbrough, T. K., Lord, R. G., \& Schyns, B. (2015). Reconsidering the accuracy of follower leadership ratings. The Leadership Quarterly, 26(2), 220-237. 
https://doi.org/10.1016/j.leaqua.2014.11.006

Harms, P. D., Credé, M., Tynan, M., Leon, M., \& Jeung, W. (2017). Leadership and stress: A meta-analytic review. The Leadership Quarterly, 28(1), 178-194. https://doi.org/10.1016/j.leaqua.2016.10.006

Hetland, H., Sandal, G. M., \& Johnsen, T. B. (2007). Burnout in the information technology sector: Does leadership matter? European Journal of Work and Organizational Psychology, 16(1), 58-75. https://doi.org/10.1080/13594320601084558

House, R. J., \& Mitchell, T. R. (1974). Path-goal theory of leadership. Journal of Contemporary Business, 3, 81-97. http://dx.doi.org/10.2307/j.ctvpg85tk.25

Inceoglu, I., Thomas, G., Chu, C., Plans, D., \& Gerbasi, A. (2018). Leadership behavior and employee well-being: An integrated review and a future research agenda. Leadership Quarterly, 29, 179-202. https://doi.org/10.1016/j.leaqua.2017.12.006

Kahai, S. S., Sosik, J. J., \& Avolio, B. J. (2004). Effects of participative and directive leadership in electronic groups. Group \& Organization Management, 29(1), 67-105. https://doi.org/10.1177/1059601103252100

Kerr, S., \& Jermier, J. M. (1978). Substitutes for leadership: Their meaning and measurement. Organizational Behavior and Human Performance, 22(3), 375-403. https://doi.org/10.1016/0030-5073(78)90023-5

Koziel, R., Friedrich, J. C., Rudolph, C. W., \& Zacher, H. (2021). Age-differentiated leadership and healthy aging at work: Evidence from the early stages of the COVID-19 pandemic. International Journal of Environmental Research and Public Health, 18(23), 12509. doi:10.3390/ijerph182312509

Kuoppala, J., Lamminpää, A., Liira, J., \& Vainio, H. (2008). Leadership, job well-being, and 
health effects - A systematic review and a meta-analysis. Journal of Occupational and Environmental Medicine, 50, 904-915. https://doi.org/10.1097/JOM0b013e31817e918d

Lang, J., Bliese, P. D., Lang, J. W. B., \& Adler, A. B. (2011). Work gets unfair for the depressed: Cross-lagged relations between organizational justice perceptions and depressive symptoms. Journal of Applied Psychology, 96(3), 602-618. https://doi.org/10.1037/a0022463

Latham, G. P., \& Locke, E. A. (1991). Self-regulation through goal setting. Organizational Behavior and Human Decision Processes, 50(2), 212-247. https://doi.org/10.1016/0749$\underline{5978(91) 90021-K}$

Lazarus, R., \& Folkman, S. (1984). Stress, appraisal, and coping. New York, NY: Springer.

Li, G., Liu, H., \& Luo, Y. (2018). Directive versus participative leadership: Dispositional antecedents and team consequences. Journal of Occupational and Organizational Psychology, 91(3), 645-664. https://doi.org/10.1111/joop.12213

Locke, E. A., \& Latham, G. P. (2006). New directions in goal-setting theory. Current Directions in Psychological Science, 15(5), 265-268. https://doi.org/10.1111/j.1467$\underline{8721.2006 .00449 . x}$

Lonigan, C. J., Phillips, B. M., \& Hooe, E. S. (2003). Relations of positive and negative affectivity to anxiety and depression in children: Evidence from a latent variable longitudinal study. Journal of Consulting and Clinical Psychology, 71, 465-481. https://doi.org/10.1037/0022-006X.71.3.465

Lord, R. G., Day, D. V., Zaccaro, S. J., Avolio, B. J., \& Eagly, A. H. (2017). Leadership in applied psychology: Three waves of theory and research. Journal of Applied Psychology, 102(3), 434- 451. https://doi.org/10.1037/ap10000089 
Manz, C. C., \& Sims, H. P. (1987). Leading workers to lead themselves: The external leadership of self-managing work teams. Administrative Science Quarterly, 32(1), 106-129. http://dx.doi.org/10.2307/2392745

Martin, S. L., Liao, H., \& Campbell, E. M. (2013). Directive versus empowering leadership: A field experiment comparing impacts on task proficiency and proactivity. Academy of Management Journal, 56(5), 1372-1395. https://10.5465/amj.2011.0113

Maslach, C. (1982). Burnout: The cost of caring. Englewood Cliffs, NJ: Prentice-Hall.

Montano, D., Reeske, A., Franke, F., \& Hüffmeier, J. (2017). Leadership, followers’ mental health and job performance in organizations: A comprehensive meta-analysis from an occupational health perspective. Journal of Organizational Behavior, 38(3), 327-350. https://doi.org/10.1002/job.2124

Mulder, J. D., \& Hamaker, E. L. (2021). Three extensions of the random intercept cross-lagged panel model. Structural Equation Modeling: A Multidisciplinary Journal, 1-11. https://doi.org/10.1080/10705511.2020.1784738

Nielsen, K., Randall, R., Yarker, J., \& Brenner, S. O. (2008). The effects of transformational leadership on followers' perceived work characteristics and psychological well-being: A longitudinal study. Work \& Stress, 22, 16-32. https://doi.org/10.1080/02678370801979430

Niessen, C., Mäder, I., Stride, C., \& Jimmieson, N. L. (2017). Thriving when exhausted: The role of perceived transformational leadership. Journal of Vocational Behavior, 103, 41-51. https://doi.org/10.1016/j.jvb.2017.07.012

Orth, U., Clark, D. A., Donnellan, M. B., \& Robins, R. W. (2021). Testing prospective effects in longitudinal research: Comparing seven competing cross-lagged models. Journal of Personality and Social Psychology, 120, 1013-1034. http://dx.doi.org/10.1037/pspp0000358 
Ouweneel, E., Le Blanc, P. M., \& Schaufeli, W. B. (2012a). Don't leave your heart at home: Gain cycles of positive emotions, resources, and engagement at work. Career Development International, 17(6), 537-556. https://doi.org/10.1108/13620431211280123

Ouweneel, E., Le Blanc, P. M., Schaufeli, W. B., \& van Wijhe, C. I. (2012b). Good morning, good day: A diary study on positive emotions, hope, and work engagement. Human Relations, 65(9), 1129-1154. https://doi.org/10.1177/0018726711429382

Park, J. G., Kim, J. S., Yoon, S. W., \& Joo, B. K. (2017). The effects of empowering leadership on psychological well-being and job engagement. Leadership \& Organization Development Journal, 38(3), 350-367. https://doi.org/10.1108/LODJ-08-2015-0182

Rafferty, A. E., \& Griffin, M. A. (2006). Refining individualized consideration: Distinguishing developmental leadershipand supportive leadership. Journal of Occupational and Organizational Psychology, 79(1), 37-61. https://doi.org/10.1348/096317905X36731

Rauthmann, J. F., Sherman, R. A., \& Funder, D. C. (2015). Principles of situation research: Towards a better understanding of psychological situations. European Journal of Personality, 29(3), 363-381. https://doi.org/10.1002/per.1994

Rauvola, R. S., Rudolph, C. W., \& Zacher, H. (2021). Handling time in occupational stress and well-being research: Considerations, examples, and recommendations. In P. D. Harms, P. L. Perrewé, \& C.-H. Chang, \& (Eds.), Research in occupational stress and well-being (Vol. 19, pp. 105-135). Bingley, UK: Emerald.

Rich, B. L., Lepine, J. A., \& Crawford, E. R. (2010). Job engagement: Antecedents and effects on job performance. Academy of Management Journal, 53(3), 617-635. http://dx.doi.org/10.5465/amj.2010.51468988

Rosseel, Y. (2012). lavaan: An R package for structural equation modeling. Journal of Statistical 
Software, 48(2), 1-36. Retrieved from http://www.jstatsoft.org/v48/i02

Rudolph, C. W., Katz, I. M., Ruppel, R., \& Zacher, H. (2021). A systematic and critical review of research on respect in leadership. The Leadership Quarterly, 32(1), 101492. https://doi.org/10.1016/j.leaqua.2020.101492

Rudolph, C. W., Murphy, L. D., \& Zacher, H. (2020). A systematic review and critique of research on "healthy leadership". The Leadership Quarterly, 31(1), 101335. doi: https://doi.org/10.1016/j.leaqua.2019.101335

Rudolph, C. W., \& Zacher, H. (2021). Family demands and satisfaction with family life during the COVID-19 pandemic. Couple and Family Psychology: Research and Practice. Advance online publication. https://doi.org/10.1037/cfp0000170

Russell, J. A. (1980). A circumplex model of affect. Journal of Personality and Social Psychology, 39(6), 1161-1178. https://doi.org/10.1037/h0077714

Scherer, K. R., \& Moors, A. (2019). The emotion process: Event appraisal and component differentiation. Annual Review of Psychology, 70(1), 719-745. https://doi.org/10.1146/annurev-psych-122216-011854

Schyns, B., \& Schilling, J. (2013). How bad are the effects of bad leaders? A meta-analysis of destructive leadership and its outcomes. The Leadership Quarterly, 24(1), 138-158. https://doi.org/10.1016/j.leaqua.2012.09.001

Sims, H. P., Faraj, S., \& Yun, S. (2009). When should a leader be directive or empowering? How to develop your own situational theory of leadership. Business Horizons, 52(2), 149-158. https://doi.org/10.1016/j.bushor.2008.10.002

Skakon, J., Nielsen, K., Borg, V., \& Guzman, J. (2010). Are leaders' well-being, behaviours and style associated with the affective well-being of their employees? A systematic review of 
three decades of research. Work \& Stress, 24(2), 107-139.

https://doi.org/10.1080/02678373.2010.495262

Spector, P. E. (1986). Perceived control by employees: A meta-analysis of studies concerning autonomy and participation at work. Human Relations, 39(11), 1005-1016. https://doi.org/10.1177/001872678603901104

Spector, P. E., \& Jex, S. M. (1998). Development of four self-report measures of job stressors and strain: Interpersonal conflict at work scale, organizational constraints scale, quantitative workload inventory, and physical symptoms inventory. Journal of Occupational Health Psychology 3(4), 356-367. http://dx.doi.org/10.1037/1076-8998.3.4.356

Stogdill, R. M. (1950). Leadership, membership and organization. Psychological Bulletin, 47(1), 1-14. http://dx.doi.org/10.1037/h0053857

Stordeur, S., D'Hoore, W., \& Vandenberghe, C. (2001). Leadership, organizational stress, and emotional exhaustion among hospital nursing staff. Journal of Advanced Nursing, 35(4), 533-542. https://doi.org/10.1046/j.1365-2648.2001.01885.x

Tuckey, M. R., Bakker, A. B., \& Dollard, M. F. (2012). Empowering leaders optimize working conditions for engagement: A multilevel study. Journal of Occupational Health Psychology, 17(1), 15-27. https://doi.org/10.1037/a0025942

Uhl-Bien, M. (2003). Relationship development as a key ingredient for leadership development. In S. E. Murphy \& R. E. Riggio (Eds.), The future of leadership development (pp. 129147). Mahwah, NJ: Lawrence Erlbaum.

Van Dam, A. (2021). A clinical perspective on burnout: Diagnosis, classification, and treatment of clinical burnout. European Journal of Work and Organizational Psychology. https://doi.org/10.1080/1359432X.2021.1948400 
Vecchio, R. P., Justin, J. E., \& Pearce, C. L. (2010). Empowering leadership: An examination of mediating mechanisms within a hierarchical structure. The Leadership Quarterly, 21(3), 530-542. https://doi.org/10.1016/j.leaqua.2010.03.014

Volmer, J., Niessen, C., Spurk, D., Linz, A., \& Abele, A. E. (2011). Reciprocal relationships between leader-member exchange (LMX) and job satisfaction: A cross-lagged analysis. Applied Psychology, 60(4), 522-545. https://doi.org/10.1111/j.1464-0597.2011.00446.x

Webster, V., Brough, P., \& Daly, K. (2016). Fight, flight or freeze: Common responses for follower coping with toxic leadership. Stress and Health, 32(4), 346-354. https://doi.org/10.1002/smi.2626

Xanthopoulou, D., Bakker, A. B., Demerouti, E., \& Schaufeli, W. B. (2009). Reciprocal relationships between job resources, personal resources, and work engagement. Journal of Vocational Behavior, 74(3), 235-244. https://doi.org/10.1016/j.jvb.2008.11.003

Yang, C. (2014). Does ethical leadership lead to happy workers? A study on the impact of ethical leadership, subjective well-being, and life happiness in the Chinese culture. Journal of Business Ethics, 123(3), 513-525. https://doi.org/10.1007/s10551-013-1852-6

Zacher, H. \& Rudolph, C. W. (2021a). Big Five traits as predictors of perceived stressfulness of the COVID-19 pandemic. Personality and Individual Differences, 175, 110694. doi:10.1016/j.paid.2021.110694

Zacher, H. \& Rudolph, C. W. (2021b). Individual differences and changes in subjective well being during the early stages of the COVID-19 pandemic. American Psychologist, 76(1), 50-62. doi: $\underline{10.1037 / \mathrm{amp} 0000702}$

Zacher, H., Rudolph, C. W., \& Posch, M. (2021). Individual differences and changes in selfreported work performance during the early stages of the COVID-19 pandemic. 
Zeitschrift für Arbeits- und Organisationspsychologie, 65(4), 188-201. doi:10.026/0932$\underline{4089 / \mathrm{a} 000365}$ 
Table 1. Summary of Participant Demographic Characteristics for Incomplete and Complete Responders

\begin{tabular}{|c|c|c|}
\hline & $\begin{array}{c}\text { Incomplete } \\
(n=829)\end{array}$ & $\begin{array}{c}\text { Complete } \\
(n=1,610)\end{array}$ \\
\hline \multicolumn{3}{|l|}{ Sex } \\
\hline Male & $101(12.2 \%)$ & $874(54.3 \%)$ \\
\hline Female & $185(22.3 \%)$ & $730(45.3 \%)$ \\
\hline Missing & $543(65.5 \%)$ & $6(0.4 \%)$ \\
\hline \multicolumn{3}{|l|}{ Age (Years) } \\
\hline Mean (SD) & $46.9(13.6)$ & $43.7(11.2)$ \\
\hline Median [Min, Max] & $49.0[19.0,99.0]$ & $44.0[18.0,69.0]$ \\
\hline Missing & $539(65.0 \%)$ & $1(0.1 \%)$ \\
\hline \multicolumn{3}{|l|}{ Education } \\
\hline Lower Secondary School & $31(3.7 \%)$ & $112(7.0 \%)$ \\
\hline Intermediate Secondary School & $96(11.6 \%)$ & $583(36.2 \%)$ \\
\hline Upper Secondary School & $50(6.0 \%)$ & $281(17.5 \%)$ \\
\hline College/University or Technical College & $109(13.1 \%)$ & $618(38.4 \%)$ \\
\hline Missing & $543(65.5 \%)$ & $16(1.0 \%)$ \\
\hline \multicolumn{3}{|l|}{ Monthly Household Income (Euros/Month) } \\
\hline $0-999$ & $54(6.5 \%)$ & $92(5.7 \%)$ \\
\hline $1000-1999$ & $56(6.8 \%)$ & $262(16.3 \%)$ \\
\hline 2000-2999 & $58(7.0 \%)$ & $369(22.9 \%)$ \\
\hline $3000-3999$ & $52(6.3 \%)$ & $346(21.5 \%)$ \\
\hline $4000-4999$ & $38(4.6 \%)$ & $284(17.6 \%)$ \\
\hline $5000-5999$ & $19(2.3 \%)$ & $134(8.3 \%)$ \\
\hline $6000-6999$ & $13(1.6 \%)$ & $122(7.6 \%)$ \\
\hline Missing & $539(65.0 \%)$ & $1(0.1 \%)$ \\
\hline \multicolumn{3}{|l|}{ Organizational Tenure (Years) } \\
\hline Mean (SD) & $11.2(9.77)$ & $12.1(10.3)$ \\
\hline Median [Min, Max] & $8.00[0,38.0]$ & $9.00[0,48.0]$ \\
\hline Missing & $797(96.1 \%)$ & $27(1.7 \%)$ \\
\hline
\end{tabular}


Table 2. Intercorrelations Among Study Variables

\begin{tabular}{|c|c|c|c|c|c|c|c|c|c|c|c|c|c|c|c|c|}
\hline & Variable Name & $\mathbf{n}$ & Mean & SD & 1. & 2. & 3. & 4. & 5. & 6. & 7. & 8. & 9. & 10. & 11. & 12. \\
\hline 1. & T1 Directive Leadership & 1,521 & 3.612 & 1.305 & .846 & & & & & & & & & & & \\
\hline 2. & T2 Directive Leadership & 1,183 & 3.632 & 1.332 & .594 & .851 & & & & & & & & & & \\
\hline 3. & T3 Directive Leadership & 1,062 & 3.628 & 1.327 & .588 & .602 & .859 & & & & & & & & & \\
\hline 4. & T1 Empowering Leadership & 1,521 & 4.186 & 1.275 & .531 & .349 & .372 & .857 & & & & & & & & \\
\hline 5. & T2 Empowering Leadership & 1,183 & 4.226 & 1.321 & .338 & .568 & .366 & .566 & .878 & & & & & & & \\
\hline 6. & T3 Empowering Leadership & 1,062 & 4.185 & 1.303 & .291 & .344 & .566 & .566 & .595 & .884 & & & & & & \\
\hline 7. & T1 Emotional Engagement & 1,609 & 4.696 & 1.302 & .112 & .139 & .127 & .239 & .261 & .293 & .904 & & & & & \\
\hline 8. & T2 Emotional Engagement & 1,208 & 4.662 & 1.318 & .105 & .136 & .158 & .211 & .295 & .333 & .651 & .913 & & & & \\
\hline 9. & T3 Emotional Engagement & 1,085 & 4.534 & 1.386 & .088 & .118 & .197 & .213 & .219 & .365 & .612 & .653 & .922 & & & \\
\hline 10. & T1 Emotional Fatigue & 1,595 & 3.169 & 1.552 & .126 & .121 & .063 & -.091 & -.066 & -.168 & -.236 & -.226 & -.240 & .902 & & \\
\hline 11. & T2 Emotional Fatigue & 1,204 & 3.118 & 1.508 & .103 & .132 & .029 & -.070 & -.049 & -.126 & -.177 & -.208 & -.219 & .661 & .900 & \\
\hline 12. & T3 Emotional Fatigue & 1,081 & 2.814 & 1.580 & .114 & .094 & .126 & -.056 & -.044 & -.091 & -.175 & -.176 & -.203 & .629 & .651 & .935 \\
\hline
\end{tabular}

Note. $r_{x y} \geq|-.063|$ are $p<.05$. Coefficient alpha reliability estimates are listed in the diagonal. Additional descriptive statistics, including complete panel correlations are available in our online appendix. 
Table 3. Relevant Parameters from Constrained RI-CLPM

\begin{tabular}{|c|c|c|c|c|c|c|c|c|c|c|}
\hline \multirow[b]{2}{*}{ Predictor } & \multirow{2}{*}{\multicolumn{2}{|c|}{ Outcome }} & \multirow[b]{2}{*}{$\boldsymbol{B}_{\text {raw }}$} & \multirow[b]{2}{*}{$S E_{B}$} & \multicolumn{6}{|c|}{$95 \% \mathrm{CI}$} \\
\hline & & & & & $Z$ & $p$-value & Lower & Upper & $B_{\text {std }}$ & $R_{\text {within }}^{2}$ \\
\hline Directive Leadership $T_{k}$ & $\rightarrow$ & Directive Leadership $T_{k+1}$ & .005 & .051 & .103 & .918 & -.095 & .106 & .005 & .016 \\
\hline Empowering Leadership $T_{k}$ & $\rightarrow$ & Directive Leadership $\mathrm{T}_{\mathrm{k}+1}$ & .017 & .043 & .406 & .685 & -.066 & .101 & .017 & \\
\hline Emotional Engagement $T_{k}$ & $\rightarrow$ & Directive Leadership $\mathrm{T}_{\mathrm{k}+1}$ & .128 & .042 & 3.066 & .002 & .046 & .209 & .122 & \\
\hline Emotional Fatigue $T_{k}$ & $\rightarrow$ & Directive Leadership $\mathrm{T}_{\mathrm{k}+1}$ & -.005 & .036 & -.138 & .890 & -.076 & .066 & -.006 & \\
\hline Directive Leadership $T_{k}$ & $\rightarrow$ & Empowering Leadership $T_{k+1}$ & .059 & .045 & 1.312 & .189 & -.029 & .146 & .056 & .027 \\
\hline Empowering Leadership $\mathrm{T}_{\mathrm{k}}$ & $\rightarrow$ & Empowering Leadership $T_{k+1}$ & -.004 & .051 & -.084 & .933 & -.105 & .096 & -.004 & \\
\hline Emotional Engagement $T_{k}$ & $\rightarrow$ & Empowering Leadership $T_{k+1}$ & .143 & .043 & 3.354 & .001 & .059 & .226 & .135 & \\
\hline Emotional Fatigue $T_{k}$ & $\rightarrow$ & Empowering Leadership $T_{k+1}$ & .072 & .037 & 1.939 & .053 & -.001 & .144 & .077 & \\
\hline Directive Leadership $T_{k}$ & $\rightarrow$ & Emotional Engagement $T_{k+1}$ & .100 & .043 & 2.309 & .021 & .015 & .185 & .094 & .030 \\
\hline Empowering Leadership $\mathrm{T}_{\mathrm{k}}$ & $\rightarrow$ & Emotional Engagement $T_{k+1}$ & -.065 & .042 & -1.548 & .122 & -.148 & .017 & -.062 & \\
\hline Emotional Engagement $T_{k}$ & $\rightarrow$ & Emotional Engagement $T_{k+1}$ & .156 & .050 & 3.106 & .002 & .057 & .254 & .156 & \\
\hline Emotional Fatigue $T_{k}$ & $\rightarrow$ & Emotional Engagement $T_{k+1}$ & .007 & .036 & .186 & .852 & -.063 & .077 & .007 & \\
\hline Directive Leadership $T_{k}$ & $\rightarrow$ & Emotional Fatigue $T_{k+1}$ & -.036 & .049 & -.739 & .460 & -.131 & .059 & -.031 & .016 \\
\hline Empowering Leadership $T_{k}$ & $\rightarrow$ & Emotional Fatigue $T_{k+1}$ & .070 & .047 & 1.501 & .133 & -.021 & .162 & .061 & \\
\hline Emotional Engagement $T_{k}$ & $\rightarrow$ & Emotional Fatigue $T_{k+1}$ & .061 & .045 & 1.351 & .177 & -.028 & .150 & .052 & \\
\hline Emotional Fatigue $T_{k}$ & $\rightarrow$ & Emotional Fatigue $\mathrm{T}_{\mathrm{k}+1}$ & .109 & .049 & 2.211 & .027 & .012 & .206 & .106 & \\
\hline
\end{tabular}

Note. $B_{\text {raw }}=$ raw regression weight, $S E_{B}=$ standard error of raw regression weight; $95 \% \mathrm{CI}=95 \%$ confidence interval, $B_{\text {std }}=$ standardized regression weight. 
Figure 1. Random Intercepts Cross-Lagged Panel Model-Simplified Representation

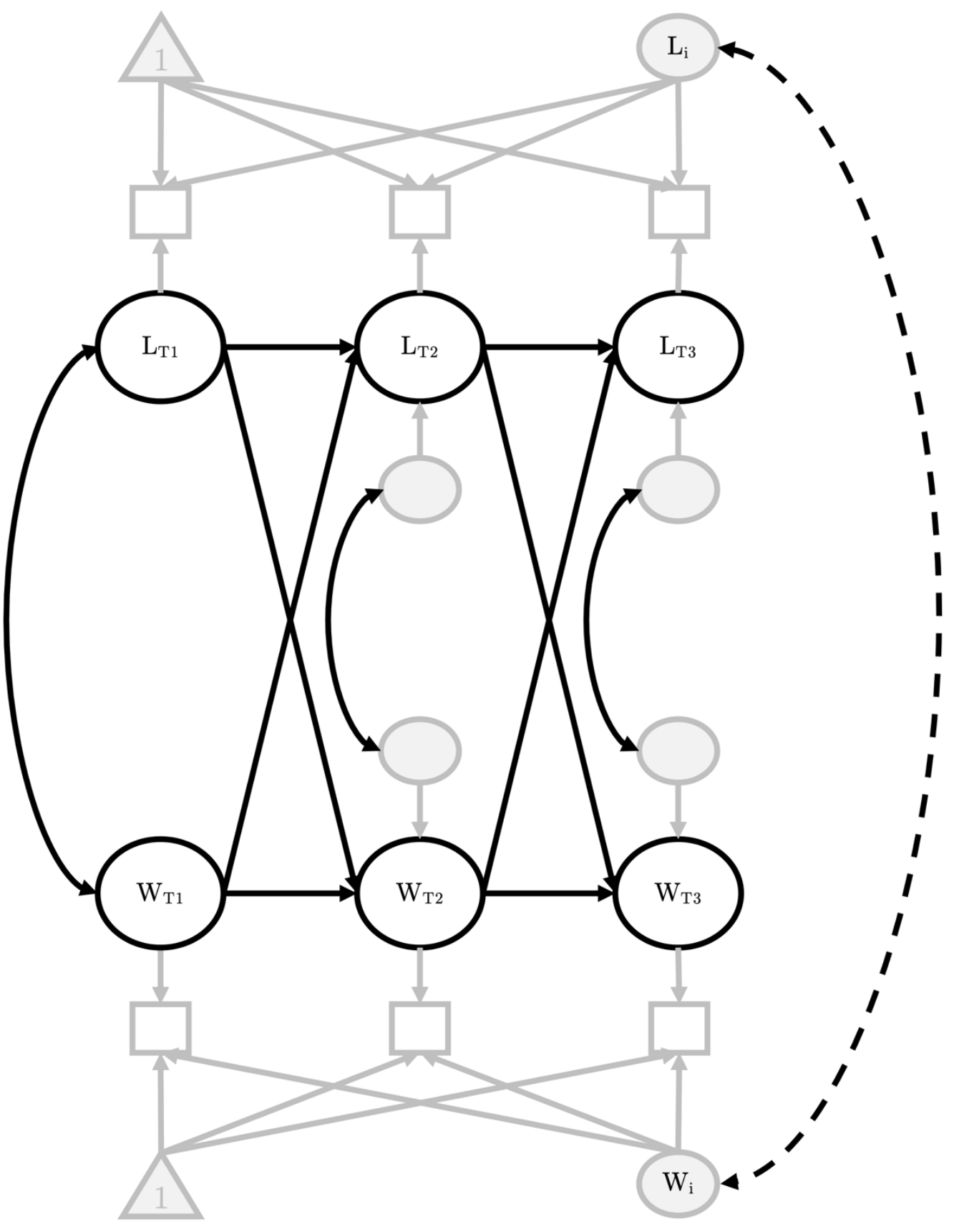

Note. For the sake of simplifying this representation "perceived leadership" (L) and "employee wellbeing" (W) variables are combined; in our statistical model, these variables are treated separately. $\mathrm{L}_{\mathrm{T} 1}-\mathrm{L}_{\mathrm{T} 3}$ represents measurement of perceived leadership (i.e., directive and empowering) over time. $\mathrm{W}_{\mathrm{T} 1}-\mathrm{W}_{\mathrm{T} 3}$ represents measurement of employee wellbeing (i.e., emotional engagement and fatigue) over time. $\mathrm{L}_{\mathrm{i}}$ and $\mathrm{W}_{\mathrm{i}}$ represent random intercepts (i.e., between-person effects) for leadership and wellbeing, respectively. Solid (dashed) directional arrow represent within-person (between-person) parameter estimates. This figure was adapted from Hamaker et al. (2015). Certain parameters have been omitted from this representation for sake of parsimony. 